\title{
Concentrations of TATA box-binding protein (TBP)-type genes affect chordamesodermal gene expression
}

\author{
TOSHIYASU GOTO ${ }^{1,2}$, RAY KELLER ${ }^{2}$ and MAKOTO ASASHIMA*,1,3 \\ 'ICORP Organ Regeneration Project, Japan Science and Technology Agency (JST), Tokyo, Japan, \\ ${ }^{2}$ Department of Biology, Gilmer Hall, University of Virginia, Charlottesville, Virginia, USA and \\ ${ }^{3}$ Department of Life Sciences (Biology), Graduate School of Arts and Sciences, The University of Tokyo, Tokyo, Japan
}

\begin{abstract}
The TATA box-binding protein (TBP) is an essential component of transcription initiation complexes of all three eukaryotic RNA polymerases. Recent knockdown studies revealed that basic transcription factors are essential not only for gene transcription but also for regulating specific gene expression. However, the mechanism of and the effect by regulation of TBP expression are unknown during early embryogenesis. Here we show that the alteration of concentration of each TBP-type gene affected mutually one another's expression, suggesting that an optimal ratio of concentrations of TBP-type genes induce expression of specific genes.
\end{abstract}

KEY WORDS: TBP, TBP2, TLF, gene expression, Xenopus laevis

\section{Introduction}

The TATA box-binding protein (TBP) is an essential component of transcription initiation complexes of all three eukaryotic RNA polymerases, and is highly conserved among yeast, plants, invertebrates and vertebrates (Cormack and Struhl. 1992, Roeder 1996, Davidson 2003). In vertebrates, three TBP-type genes, TBP, TLF/ TRF2and TBP2/TRF3 have been isolated and studied (Veenstra et al., 2000, Jallow etal., 2004, Dantonel etal., 1999). TBP2 has a highly conserved core domain at the C-terminus, which binds to the TATA box-binding domain, similar to TBP (Jallow et al., 2004, Bartfai et al., 2004). The core domain of TBP-like factor (TLF) is notably different from that of TBP, and although it interacts with TFIIA and TFIIB, TLF does not bind to the canonical TATA box-binding domain (Bartfai et al., 2004, Rabenstein et al., 1999, Teichmann et al., 1999, Moore et al., 1999). Recent studies demonstrated that TBP-type genes are not just essential for gene expression but can also regulate specific gene expression (Veenstra et al., 2000, Jallow et al., 2004, Bartfai et al., 2004). However, those results derived from knockdown experiments, experiments with various concentrations of TBP-type genes including their over-expressions are not performed yet. Here we show that concentrations of TBP-type genes affect the regulation of gene expression during embryogenesis.

\section{Results}

It has been previously reported that injection of the antisence oligonucleotide of TBPinto 1-cell stage embryo arrested development before complete of gastrulation but not affected expression of Xbraat late gastrula stage (st.13) (Veenstra et al., 2000). On the other hand, $X b r a$ is required for normal gastrulation movements (Wilson et al., 1995, Conlon and Smith, 1999). We considered that injection at 1-cell stage would not let the antisence oligonucleotide of $T B P$ spread well to the future Xbraexpressing region. To reconfirm whether a knockdown of TBPaffects expression of $X b r a$, we injected antisense morpholino oligonucleotide of TBP (TBP$\mathrm{MO}$ ) into the future marginal zone region of all blastomeres of the 4-cell embryo. Injection of TBP-MO (10 ng/blatomere) decreased expression of $X b r a$ (Fig. 1A, right lane) in contrast to previous report (Veenstra et al., 2000). This result suggested that the antisense oligonucleotide would not spread throughout embryo, and the injected region is very important to study the function of its gene. Moreover, we found over-expression ( $700 \mathrm{pg} / \mathrm{blasomere})$ of $T B P$ also reduced $X b r a$ expression (Fig. $1 \mathrm{~A}$, left lane). Taken together, these results suggested that TBP would affect early embryogenesis.

Over-expression of TBP targeted to the future marginal zone region of dorsal blastomeres of the 4-cell embryo interfered with head formation and shortened the dorsal axis, like UV-irradiated embryos (Mise and Wakahara, 1994, Medina et al., 1997) (Fig. 1C). Ventral over-expression of TBPhad no effect on embryogen-

Abbreviations used in this paper: MO, morpholino; TBP, TATA binding protein; TLF, TBP-like factor.

\footnotetext{
*Address correspondence to: Makoto Asashima. Department of Life Sciences (Biology), Graduate School of Arts and Sciences, The University of Tokyo, 38-1 Komaba, Meguro-ku, Tokyo 153-8902, Japan. Fax: +81-3-5454-6698 e-mail: asashi@bio.c.u-tokyo.ac.jp
} 
esis (Fig. 1D). In addition, dorsal injection of TBP-MO interfered with axis formation (Fig. 1E), while ventral injection of TBP-MO had no significant effect on axis formation (Fig. 1F). These results suggested that TBPmight play an important role in axis formation at the dorsal side, in contrast to previous report that the antisense oligonucleotide of TBP interfered with complete of gastrulation (Veenstra et al., 2000). Since many chordamesodermal genes

\section{A}
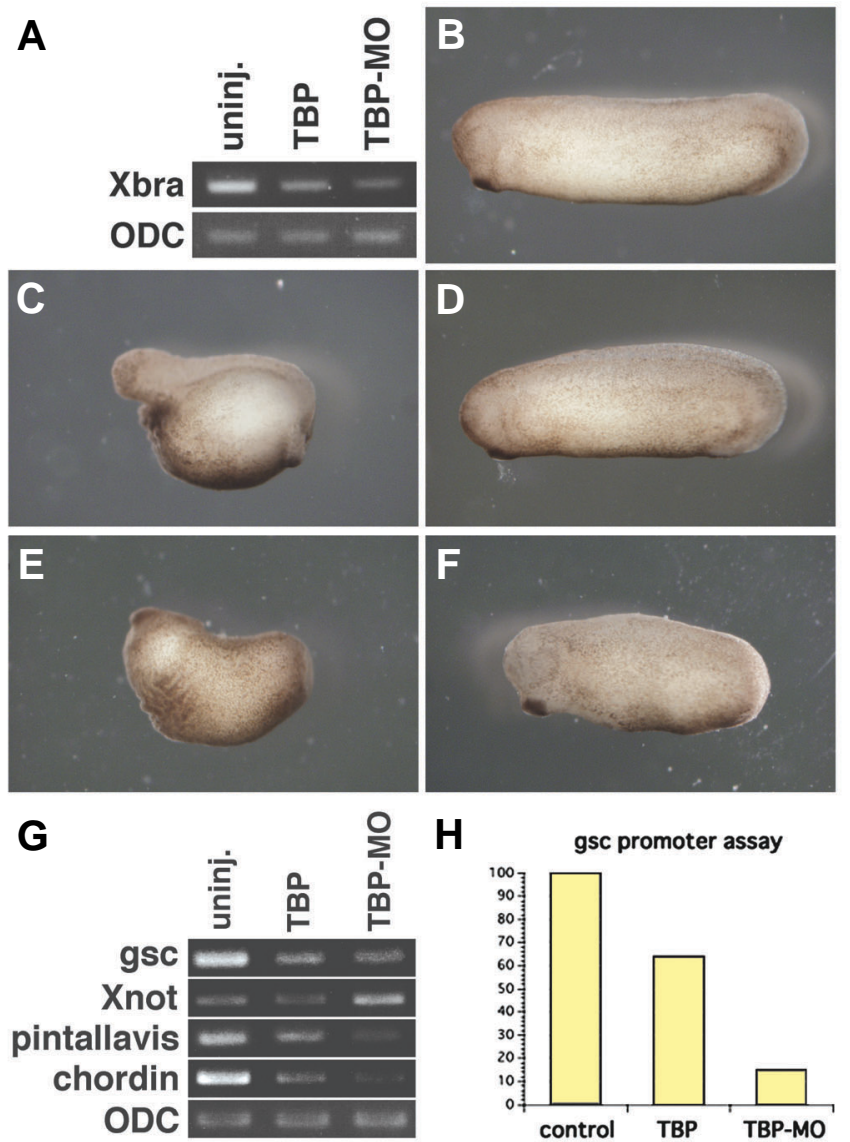

$\mathbf{H}$

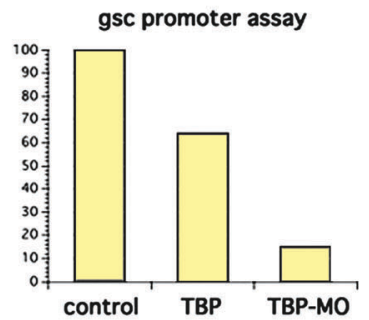

are related to axis formation (Cho et al., 1991, Sasai et al., 1994, Yasuo and Lemaire, 2001, O'Reilly et al., 1995), we next tested whether TBPreduce expressions of dorsal genes, such as goosecoid, pintallavis, chordinand Xnot. Dorsal over-expression of TBP reduced expression of goosecoid, pintallavis and chordin (Fig. $1 \mathrm{G}$, center lane). Dorsal injection of TBP-MO also decreased expression of goosecoid, pintallavis and chordin (Fig. 1G, right lane). Furthermore, the promoter of goosecoidincluded a TATA box-binding site, and its promoter assay also demonstrates that both over-expression of TBPand injection of TBP-MO decreased transcription of goosecoid(Fig. $1 \mathrm{H}$ ). However expression of Xnot

A

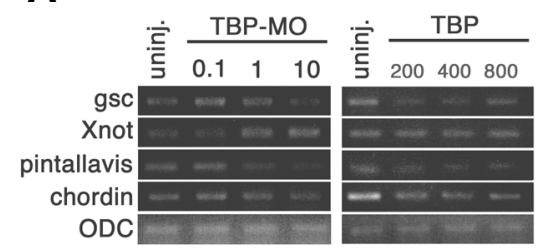

B

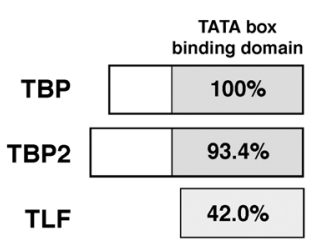

$\mathbf{E}$

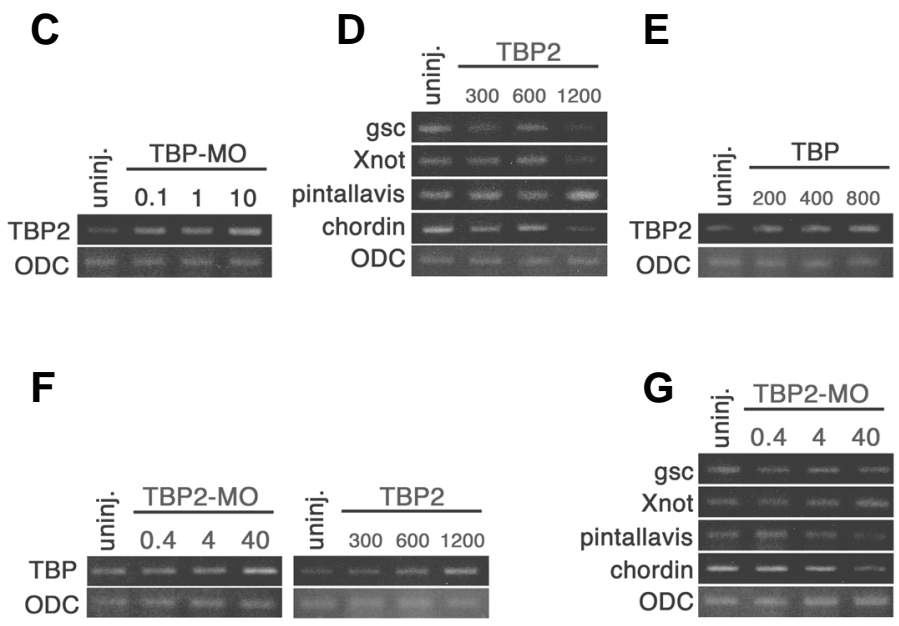

Fig. 1. Over-expression and repletion of TBP inhibits axis formation. (A) Both over-expression of TBP and high-dose injection of TBP-MO into the future marginal zone region of all blastomeres of the 4-cell embryo reduced expression of Xbra. (B) Control embryo (st. 30). (C) Over-expression of TBP (700 pg/blastomere) into the future marginal zone region of dorsal blastomeres of the 4-cell embryo interfered with axis formation, including a short axis and absence of most of the head. (D) Over-expression into the ventral blastomeres of the 4-cell embryo had no effect on embryogenesis. (E) High-dose injection of TBP-MO (10 ng/blastomere) into the marginal zone region of dorsal blastomeres of 4-cell embryo also interfered with axis formation. (F) High-dose injection of TBP-MO into the ventral blastomeres of the 4-cell embryo had no significant effect on embryogenesis. (G) Overexpression of TBP reduced expression of chordamesodermal genes (center lane) at gastrula stage (st. 10). High-dose injection of TBP-MO reduced expression of all marker genes except for Xnot, which was increased by injection of TBP-MO. (H) Results of a luciferase assay using the reporter gene containing the promoter of goosecoid are shown. The luciferase activity was decreased by both over-expression of TBP and injection of TBP-MO at stage 10 .

Fig. 2. Optimal concentrations of TBP and TBP2 induced chordamesodermal gene expression at gastrula stage. (A) Effects on gene expression by the various concentrations of TBP at stage 10. Injection of TBP-MO (0.1 ng-10 ng) and over-expression of TBP mRNA (200 pg-800 pg) is indicated in left and right panels, respectively. The low-dose injection of TBP-MO (0.1 ng/blastomere) increased slightly expression of goosecoid, pintallavis and chordin, but over-expression of TBP reduced expression of goosecoid, pintallavis and chordin. Expression of Xnot increased gradually depending on the dose of TBP-MO, and was not altered by any dose of TBP. (B) Schematic of TBP-type genes. The percentage of identical amino acids in TATA binding domain is indicated in the shaded box. (C) Injection of TBP-MO increased expression of TBP2, depending on the dose of TBP-MO. (D) Expression of chordamesodermal genes was increased with middle-dose (goosecoid, Xnot and chordin) or high-dose (pintallavis) of over-expression of TBP2. (E) Over-expression of TBP also increased expression of TBP2, depending on the dose of TBP. (F) Both injection of TBP2-MO (left) and overexpression of TBP2 (right) increased expression of TBP, depending on the dose of both TBP2-MO and TBP2. (G) Expression of some chordamesodermal genes was increased with middle-dose (goosecoid and pintallavis) or high-dose (Xnot) of TBP2-MO. Expression of chordin was not altered or decreased by TBP2-MO. 

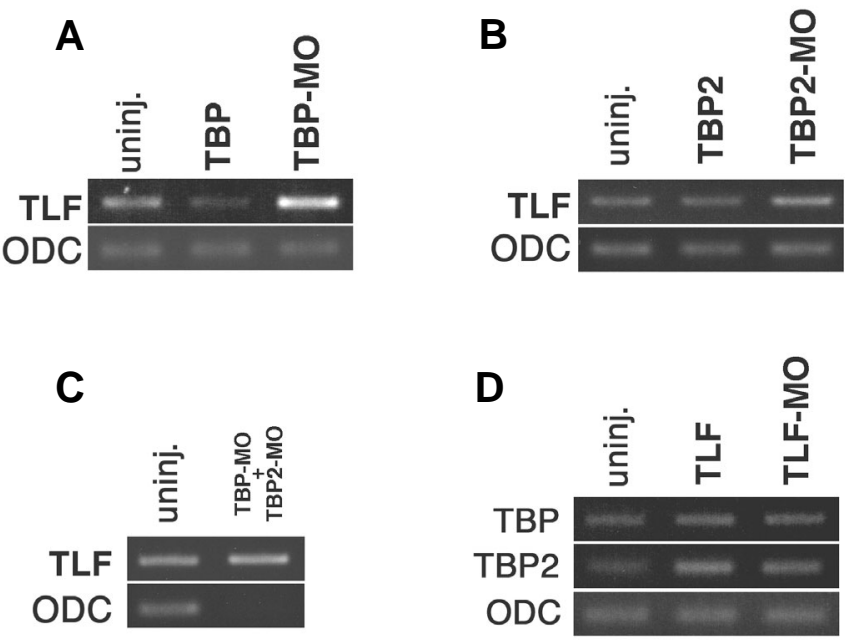

Fig. 3. The concentration of each TBP-type gene affected mutually one another's expression at gastrula stage. (A) Expression of TLF was reduced by high-dose of TBP over-expression, but increased by highdose of injection of TBP-MO. (B) Expression of TLF was not altered by high-dose of TBP2 over-expression, but increased by high-dose of injection of TBP2-MO. (C) Double injection of TBP-MO and TBP2-MO decreased expression of the internal maker, ODC. However expression of TLF was not affected by double injection. (D) Both high-dose overexpression of TLF and injection of TLF-MO increased slightly both expressions of TBP and TBP2.

was not altered by $T B P$ over-expression and induced by injection of TBP-MO (Fig. 1G). We therefore hypothesize that TBP may have very different, concentration-dependent functions. To confirm that the effect of $T B P$ on chordamesoderm gene expression is concentration-dependent, we injected various doses of $T B P$ mRNA and TBP-MO in dorsal blastomeres of the 4-cell embryo. We found that over-expression of $T B P$ at all concentrations tested reduced expression of goosecoid, pintallavis and chordin, while expression of the same genes was increased with a low-dose $(0.1$ $\mathrm{ng} /$ blastomere) injection of TBP-MO (Fig. 2A). Expression of Xnot was increased with depending on the dose of TBP-MO, and showed the same level with increasing doses of TBP overexpression (Fig. 2A). These results indicate that an appropriate low-concentration of TBP increases expression of each chordamesodermal gene. Furthermore, we proposed that another TBP-type gene is required for transcription with low-concentration of TBP. In Xenopus development, TBP2 has a highly conserved TATA box-binding domain similar to TBP (Fig. 2B), and TBP2can partly substitute for TBPfunction (Jallow et al., 2004). Therefore we considered that $T B P 2$ could replace or affect the function of $T B P$ for regulating expression of each specific gene. First, we tested whether expression of TBP2is altered with low-concentrations of TBP. Expression of TBP2 wsa increased depending on the dose of TBP-MO (Fig. 2C). And expression of goosecoid, Xnot and chordinwas increased at a middle-dose (600 ng/blastomere) of TBP2, and a high-dose (1200 ng/blastomere) of TBP2 increased pintallavis expression (Fig. 2D). These results confirmed that TBP2 could partly substitute for TBP function for several chordamesodermal gene expressions. Moreover, over-expression of TBP also increased expression of TBP2 (Fig. 2E). This result suggested that $T B P 2$ not only replaced the function of $T B P$ in the presence of low-concentration of $T B P$, but also increased its concentration to maintain a specific equilibrium between $T B P$ and TBP2 concentrations in the high-concentration of TBP. On the other hand, expression of $T B P$ was also increased by a highdose injection of TBP2-MO (Fig. 2F, left) and over-expression of TBP2(Fig. 2F, right). Expression of goosecoid, Xnotand pintallavis was increased at an appropriate dose of TBP2-MO (Fig. 2G). Expression of chordin was not altered or decreased by the injection of TBP2-MO (Fig. 2G). These results suggested that both TBP and TBP2 control each other's expression depending on the concentrations of the two, and that specific chordamesodermal genes are regulated by an optimal combination of TBP and TBP2 concentrations.

The other vertebrate TBP-type gene, TLF, has no highly conserved TATA box-binding domain (Fig. 2B), and has distinct functions from TBP (Veenstra et al., 2000, Rabenstein et al., 1999, Teichmann et al., 1999). We found over-expression of TBP reduced $T L F$ expression (Fig. $3 A$, center lane), but over-expres-
Fig. 4. The confirmation of the specificity of each morpholino. TBP-MO, TBP2-MO and TLF-MO reduced specifically translation of GFP containing sequences targeted with TBP-MO, TBP2-MO and TLF-MO at the $5^{\prime}$ '-region, respectively. GFP-TBP (250pg), GFPTBP2 (250pg) or GFP-TLF (250pg) with Alexa594-dextran (300pg) was injected in the animal pole of 4-cell embryo. The fluorescent signals were observed at stage 10. Pictures on top panels indicate the injected embryos. Pictures on center panels indicate tracer signals with Alexa594-dextran. Pictures on bottom panels indicate GFP signals. Each $M O$ reduced translation of each corresponding GFP construct, but did not reduce translation of the GFP construct containing different targeting sequence.

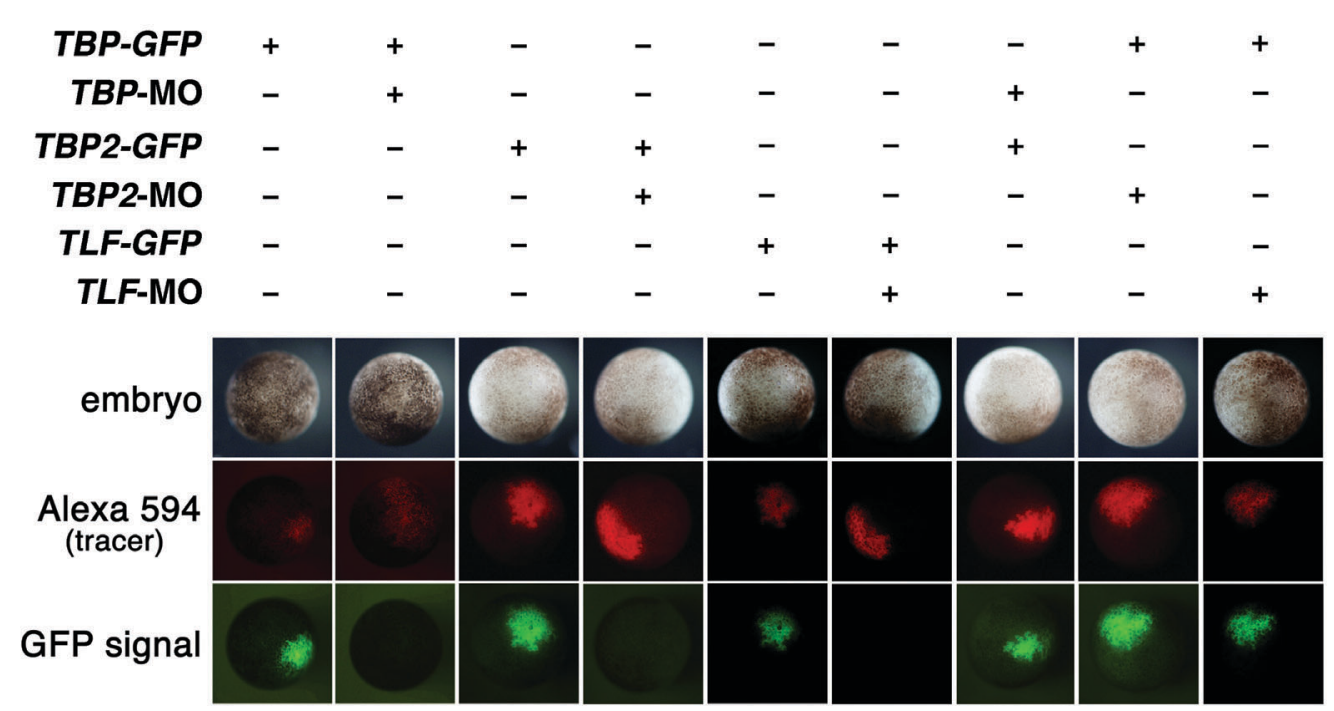


sion of TBP2had no such effect (Fig. 3B, center lane). High-dose injections of both TBP-MO and TBP2-MO increased expression of $T L F$ (Fig. 3A, B, right lanes). Furthermore, even though expression of the internal marker gene, $O D C$, was markedly decreased by double injection of TBP-MO and TBP2-MO, expression of TLF was not decreased (Fig. 3C). Both over-expression of TLFand injection of $T L F-\mathrm{MO}$ also slightly increased expression of $T B P$ and TBP2 (Fig. 3D). Taken together, these results indicated that the expression of each of the three TBP-type genes was affected mutually by expression of the other two to regulate specific gene expression in early embryogenesis.

\section{Discussion}

Although TBP2 binds to the TATA box-binding domain and partly replaces the function of TBP (Jallow et al., 2004), different gene promoters selectively recruit TBP and TBP2 (Yang et al., 2006). Although TLF dose not bind to the canonical TATA boxbinding domain, TLF and TBP compete for TFIIA and probably other general transcription factors (Chong et al., 2005). Moreover, other molecules like negative cofactor 2 (NC2), PIAS and SAGA also associated with TBP-type genes and contribute to the regulation of specific gene expression (Cang et al., 2002, Prigge and Schmidt, 2006, Sermwittayawong and Tan, 2006, Veenstra and Wolffe, 2001). Taken together, these studies indicate how functionally TBP-type genes regulate specific gene expression. However our present data indicate that TBP-type genes regulate mutually each other expression, suggesting that alteration of concentration of TBP-type genes themselves reflects regulating of expression of specific genes in early embryogenesis. Unknown upstream genes of TBP-type genes would play an important role for regulating such concentrations of them.

\section{Materials and Methods}

\section{mRNA and Morpholinos}

The coding sites of TBP (BC08819), TBP2 (AY753184) and TLF (AJ238441) were subcloned into modified pCS2+ vectors. The mRNAs were synthesized using T7 RNA polymerase. Morpholinos (MOs) for TBP (5'-tgctgttgtttgatccatgttgtg-3'), TBP2 (5'-gaagactctccatccattttgaggg-3') and TLF (5'-tgccacatcactgtcagcatccatc-3') were obtained from GENE TOOLS, LLC. To confirm the specificity of each MO, we made GFP-TBP, GFP-TBP2 and GFP-TLF constructs that contained 5' sequences that could be targeted by TBP-MO, TBP2-MO and TLF-MO respectively: the sequence of 5'-region of GFP-TBPCDNA was

5'-cacaacATGgatcaaaacaacagcagtaaaggagaagaactttt-3';

that of GFP-TBP2 cDNA was

5'-ccctcaaaATGgatggagagtcttcgagtaaaggagaagaacttt-3';

that of GFP-TLFCDNA was

5'-gATGgatgctgacagtgatgtggcaagtaaaggagaagaactttt-3'

(targeted sequences are underlined; ATG is first the methionine). (See Fig. 4)

\section{$R T-P C R$}

For RT-PCR assay, the following primers were used: the forward 5'ttgacacaacatggatcaaa-3' and reverse 5'-ctatgttctgtagctgagg-3' for TBP, the forward 5'-cttagaccaatgtgatgctg-3' and reverse 5'-tgaatcttgggtagcatctc3' for TBP2, the forward 5'- agccatctcgatggatgctg-3' and reverse 5'tcacaaaatagttttctgc-3' for TLF; the forward 5'-gcaggcacccaacaagatgat3 ' and reverse 5'-ccagattcggggtgcagagt-3' for pintallavis; 5'attgactccatcctctccag-3' and reverse 5'-ttaggctcctacagttccac-3' for Xnot. Other primers are previously described in Suzawa et al., (2007). We performed RT-PCR experiments more than three times to get results. $O D C$ was used as a loading control.

\section{Luciferase assay}

The pOLuc plasmid containing the promoter region of goosecoid (80pg) (Watabe et al., 1995) was co-injected with TBP(700pg) or TBPMO (10ng) in the animal pole of 2-cell embryos. The supernatant of homogenized embryos at stage 10 was assayed using Dual-Luciferase Reporter Assay System (Promega).

\section{Acknowledgements}

This work was supported in part by a grant from Japan Science and Technology Agency (JST), Ministry of Health, Labourand Welfare (MHLW), and Ministry of Education, Culture, Sports, Science and Technology (ECSST) (to MA) and NIH RO1 HD025594 (to RK).

\section{References}

BARTFAI, R., BALDUF, C., HILTON, T., RATHMANN, Y., HADZHIEV, Y., TORA, L., ORBAN, L. and MULLER, F. (2004). TBP2, a vertebrate-specific member of the TBP family, is required in embryonic development of zebrafish. Curr. Biol. 14: 593-598.

CANG, Y. and PRELICH, G. (2002). Direct stimulation of transcription by negative cofactor 2 (NC2) through TATA-binding protein (TBP). Proc. Natl. Acad. SCl. USA 99: 12727-12732.

CHO, K.W., BLUMBERG, B., STEINBEISSER, H. and DE ROBERTIS, E.M. (1991). Molecular nature of Spemann's organizer: the role of the Xenopus homeobox gene goosecoid. Cel/67: 1111-1120.

CHONG, J.A., MORAN, M.M., TEICHMANN, M., KACZMAREK, J.S., ROEDER, R. and CLAPHAM, D.E. (2005). TATA-binding protein (TBP)-like factor (TLF) is a functional regulator of transcription: reciprocal regulation of the neurofibromatosis type 1 and c-fos genes by TLF/TRF2 and TBP. Mol. Cell Biol. 25: 26322643.

CONLON, F.L. and SMITH, J.C. (1999). Interference with brachyury function inhibits convergent extension, causes apoptosis, and reveals separate requirements in the FGF and activin signalling pathways. Dev. Biol. 213: 85-100.

CORMACK, B.P. and STRUHL, K. (1992). The TATA-binding protein is required for transcription by all three nuclear RNA polymerases in yeast cells. Cel/69: 685696.

DANTONEL, J.C., WURTZ, J.M., POCH, O., MORAS, D. and TORA L. (1999). The TBP-like factor: an alternative transcription factor in metazoa? Trends Biochem. Sci. 24: 335-339

DAVIDSON, I. (2003). The genetics of TBP and TBP-related factors. Trends Biochem. Sci. 28: 391-398.

JALLOW, Z., JACOBI, U.G., WEEKS, D.L., DAWID, I.B. and VEENSTRA, G.J. (2004), Specialized and redundant roles of TBP and a vertebrate-specific TBP paralog in embryonic gene regulation in Xenopus. Proc. Natl. Acad. Sci. USA 101: 13525-13530.

MEDINA, A., WENDLER, S.R. and STEINBEISSER, H (1997). Cortical rotation is required for the correct spatial expression of $\mathrm{nr} 3$, sia and gsc in Xenopus embryos. Int. J. Dev. Biol. 41: 741-745.

MISE, N. and WAKAHARA, M. (1994). Dorsoventral polarization and formation of dorsal axial structures in Xenopus laevis: analyses using UV irradiation of the full-grown oocyte and after fertilization. Int. J. Dev. Biol. 38: 447-453.

MOORE, P.A., OZER, J., SALUNEK, M., JAN, G., ZERBY, D., CAMPBELL, S. and LIEBERMAN, P.M. (1999). A human TATA binding protein-related protein with altered DNA binding specificity inhibits transcription from multiple promoters and activators. Mol. Cel/ Biol. 19: 7610-7620.

O'REILLY, M.A., SMITH, J.C. and CUNLIFFE, V. (1995). Patterning of the mesoderm in Xenopus: dose-dependent and synergistic effects of Brachyury and Pintallavis. Development 121: 1351-1359.

PRIGGE, J.R. and SCHMIDT, E.E. (2006). Interaction of protein inhibitor of activated STAT (PIAS) proteins with the TATA-binding protein, TBP, J. Biol. Chem. 281: 12260-12269. 
RABENSTEIN, M.D., ZHOU, S., LIS, J.T. and TJIAN, R. (1999). TATA box-binding protein (TBP)-related factor 2 (TRF2), a third member of the TBP family. Proc. Natl. Acad. Sci. USA 96: 4791-4796.

ROEDER, R.G. (1996). The role of general initiation factors in transcription by RNA polymerase II. Trends Biochem. Sci. 21: 327-335.

SASAI, Y., LU, B., STEINBEISSER, H., GEISSERT, D., GONT, L.K. and DE ROBERTIS, E.M. (1994). Xenopus chordin: a novel dorsalizing factor activated by organizer-specific homeobox genes. Cel/79: 779-790.

SERMWITTAYAWONG, D. and TAN, S. (2006). SAGA binds TBP via its Spt8 subunit in competition with DNA: implications for TBP recruitment. EMBO J. 25 3791-3800.

SUZAWA, K., YUKITA, A., HAYATA, T., GOTO, T., DANNO, H., MICHIUE, T., $\mathrm{CHO}, \mathrm{K}$. W. and ASASHIMA, M. (2007). Xenopusglucose transporter 1 (xGLUT1) is required for gastrulation movement in Xenopus laevis. Int. J. Dev. Biol. 51: 183-90.

TEICHMANN, M., WANG, Z., MARTINEZ, E., TJERNBERG, A., ZHANG, D., VOLLMER, F., CHAIT, B.T. and ROEDER, R.G. (1999). Human TATA-binding protein-related factor-2 (hTRF2) stably associates with hTFIIA in HeLa cells. Proc. Natl. Acad. Sci. USA 96: 13720-13725.
VEENSTRA, G.J., WEEKS, D.L. and WOLFFE, A.P. (2000). Distinct roles for TBP and TBP-like factor in early embryonic gene transcription in Xenopus. Science 290: 2312-2315.

VEENSTRA, G.J. and WOLFFE, A.P. (2001). Gene-selective developmental roles of general transcription factors. Trends Biochem. Sci. 26: 665-671.

WATABE, T., KIM, S., CANDIA, A., ROTHBACHER, U., HASHIMOTO, C., INOUE, K. and CHO, K.W. (1995). Molecular mechanisms of Spemann's organizer formation: conserved growth factor synergy between Xenopus and mouse. Genes Dev. 9: 3038-3050.

WILSON, V., MANSON, L., SKARNES, W.C. and BEDDINGTON, R.S. (1995). The $T$ gene is necessary for normal mesodermal morphogenetic cell movements during gastrulation. Development 121: 877-886.

YANG, Y., CAO, J., HUANG, L., FANG, H.Y. and SHENG, H.Z. (2006). Regulated expression of TATA-binding protein-related factor 3 (TRF3) during early embryogenesis. Cell Res. 16: 610-621.

YASUO, H. and LEMAIRE, P. (2001). Role of Goosecoid, Xnot and Wnt antagonists in the maintenance of the notochord genetic programme in Xenopus gastrulae. Development 128: 3783-3793.

\section{Related, previously published Int. J. Dev. Biol. articles}

See our recent Special Issue Ear Development edited by Fernando Giraldez and Bernd Fritzsch at: http://www.ijdb.ehu.es/web/contents.php?vol=51\&issue=6-7

The N-terminus zinc finger domain of Xenopus SIP1 is important for neural induction, but not for suppression of Xbra expression Kazuhiro R. Nitta, Shuji Takahashi, Yoshikazu Haramoto, Masakazu Fukuda, Kousuke Tanegashima, Yasuko Onuma and Makoto Asashima Int. J. Dev. Biol. (2007) 51: 321-325

Heart formation and left-right asymmetry in separated right and left embryos of a newt Kazuhiro Takano, Yuzuru Ito, Shuichi Obata, Tsutomu Oinuma, Shinji Komazaki, Hiroaki Nakamura and Makoto Asashima Int. J. Dev. Biol. (2007) 51: 265-272

Xenopus glucose transporter 1 (xGLUT1) is required for gastrulation movement in Xenopus laevis Keiko Suzawa, Akira Yukita, Tadayoshi Hayata, Toshiyasu Goto, Hiroki Danno, Tatsuo Michiue, Ken W. Cho and Makoto Asashima Int. J. Dev. Biol. (2007) 51: 183-190

Bowline, a novel protein localized to the presomitic mesoderm, interacts with Groucho/TLE in Xenopus Akiko Kondow, Keisuke Hitachi, Tempei Ikegame and Makoto Asashima Int. J. Dev. Biol. (2006) 50: 473-479

Comparison of induction during development between Xenopus tropicalis and Xenopus laevis Ayako Sedohara, Keiko Suzawa and Makoto Asashima Int. J. Dev. Biol. (2006) 50: 385-392

The role of XTRAP-gamma in Xenopus pronephros development Dong-hui Li, Techuan Chan, Reiko Satow, Shinji Komazaki, Kouhei Hashizume and Makoto Asashima

Int. J. Dev. Biol. (2005) 49: 401-408

Induction of tooth and eye by transplantation of activin A-treated, undifferentiated presumptive ectodermal Xenopus cells into the abdomen

Yasufumi Myoishi, Miho Furue, Yasuto Fukui, Tetsuji Okamoto and Makoto Asashima Int. J. Dev. Biol. (2004) 48: 1105-1112

Heinz Tiedemann Obituary

Walter Knöchel, Horst Grunz, Makoto Asashima and Doris Wedlich

Int. J. Dev. Biol. (2004) 48: 1059-1060

Activin-like signaling activates Notch signaling during mesodermal induction

Takanori Abe, Miho Furue, Yasufumi Myoishi, Tetsuji Okamoto, Akiko Kondow and Makoto Asashima

Int. J. Dev. Biol. (2004) 48: 327-332

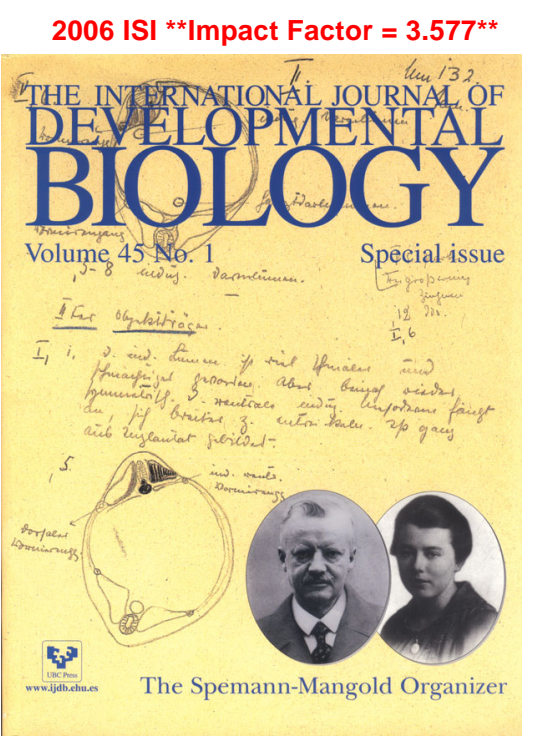

